Розин В.M.

\title{
Эволюция книги в пространстве западной культуры (От глиняной книги к электронной)
}

Аннотачия: В статье рассматривается эволючия книеи, начиная от ее происхождения в культуре Древнего мира заканчивая нашим днем. Одной из предпосылок книги выступало изобретение и развитие письменности, другой - становление личности и общества. Книга на первых этапах своего развития обеспечивала консолидацию общества, состоявшего из личностей; потом к первичной функции книги добавляются новые (виртуального путешествия, развлечения, познания и образования). Появление книги существенно повлияло на человека, способствуя формированию разных реальностей его сознания, а также новых способностей. С переходом к культуре Нового времени складываются массовые аудитории читателей и новые требования к книге, что повлекло за собой появление печатного станка и книги нового типа (большую роль здесь сыграла технологизация). В последней части статьи рассматривается вторая техническая революция, приведшая к появлению электронной книги и Интернету. Обсуждается, почему электронная книга вытесняет бумажную. Исследование, представленное в статье, предполагало проблематизацию, ситуационный анализ и целиком опиралось на метод псевдогетического анализа, позволяющего осуществить культурно-историческую реконструкцию книги. В результате исследования удалось показать, что книга прошла большую эволюцию, существенными факторами которой выступала смена культур, технические изобретения, проблемы и требования общества и личности. Книга способствовала не только консолидации общества и реализации в нем личности, но конституировала некоторые стороны сознания человека и его способности.

Review: The article is devoted to the evolution of book from the moment when it was first created in the culture of the Ancient World and up to the present. One of the prerequisites for creating a book was the invention and development of the written language and the other prerequisite was the development of personality and society. At the first stages of the development the book ensured the consolidation of society. Later the book gained other functions such as virtual traveling, entertainment, knowledge and education. The appearance of book had a considerable influence on the humanity and formed different realities of his consciousness as well as new abilities. At the beginning of the Modern Period new readers and new requirements for a book appeared which resulted in creating a printing machine and a new type of book (technology development played an important role in that process). The last part of the article is devoted to the second technical revolution which, in its turn, resulted in the creation of a eBook and Internet. The author discusses the reasons why eBook is now superseding a paper book. The research provided in the article involved problematisation and situational analysis and was entirely based on the method of pseudo-getic analysis allowing to perform the cultural and historical reconstruction of a book. As a result of the research, the author shows that a great evolution the book has had. The main drivers of the development have been the cultural shift, technological inventions, problems and requirements of the society and personality. The ebook has led not only to the consolidation of the society and realization of personality but also constituted some sides of human consciousness and abilities.

Ключевъе слова: Книга, Интернет, папирус, пергамент, бумага, общество, личность, консолидация, мышление, техника.

Keywords: Book, Internet, papyrus, parchment, paper, society, personality, consolidation, thinking, technology.

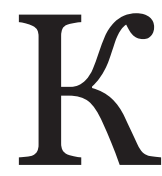

ниге пропето много восхищенных арий, но в наш век слышны мотивы сомнения и горечи. Особенно печальна судьба бумажной версии книги, когда-то, безусловно, царицы умов и души. В больших городах нередкая картина - стопка книг, часто в очень хорошем со- стоянии, выставленная хозяином у подъезда дома: берите, мол, книги бесплатно, кто хочет, пока уборщик не выбросит их в мусор. А в Интернете идет полемика - вытеснит ли электронная книга бумажную, и большинство участников склоняются к мнению, что, конечно же, вытеснит, причем многие ут- 
верждают, что бумажная книга вообще скоро станет анахронизмом и редкостью. Признаем факт: на смену бумажной книге приходит электронная, однако, скептики и старое поколение смотрит на всю эту электронику с подозрением, как бы говоря, ну какая же это книга! Ни запаха типографской краски, ни шелеста страниц, ни ощущения того, что ты держишь в руках нечто прекрасное, что вотвот состоится встреча с автором, которого ты уже чувствуешь, и уже предвкушаешь, что тебе предстоит много прекрасных часов чтения. Да разве можно рассказать нечитающим книги всю эту прелесть, красоту и лихорадку, вызванные интересной книгой?

Но оставим эмоции, речь идет об осмыслении книги и ее судьбы, осмыслении рациональном, научном, философском. Каким же образом можно осмыслить книгу, понять ее сущность, ведь важно уяснить не внешние, случайные признаки книги, как говорили в средние века акциденции, а именно сущность. Взглянем на историю книги и зададимся таким вопросом, а когда книга возникла? Известно, что уже в культуре древних царств (Шумеро-вавилонской цивилизации, Древнем Египте) появились глиняные таблички и папирусы, в которых содержались хозяйственные записи и договора, алгоритмы решения задач, позволяющие восстанавливать поля после разлива рек или преобразовывать их, и другие сведения, нужные для ведения хозяйства, в том числе царского. Были ли эти ящики с табличками и свитки папирусов первыми книгами? Вряд ли, но вот записи мифа о Гильгамеше или тексты «Вавилонской теодицеи» уже вполне можно считать первыми книгами ${ }^{1}$.

${ }^{1}$ Страдалец из «Вавилонской теодицеи» восклицает: Что получия я от бога, которому

поклонялся?

Пред тем, кто ниже меня, я склоняюсъ, Презирают меня (и) последний, (u) богатый,

А вот причина. u гордъй.

Вгляделся я в мир - дела (обстоят)

Демону бог не закрыл дороги, по-другому:

Отец по каналам волочит лодку,

(А) сын его (взрослый) разлегся в постели

(Клочков И. Духовная культура Вавилонии: человек, судьба, время. М., 1983., С. 35, 85-86).

«Понятно, - пишет Клочков, - когда страдают наказываемые богами нечестивцы, но почему участь их делит человек благочестивый?» И приводит из
Дело в том, что если, например, хозяйственные записи могут быть рассмотрены как средства деятельности (сведения, информация, знания, схемы, алгоритмы), то мифы или «Вавилонская теодицея»это нечто другое. Они были адресованы грамотным людям, знати при дворе царя, писцам и жрецам, приобретались за большие деньги для чтения, читались и обсуждались, уже были известные чтецы, а иногда даже и составители этих историй (на почве ранней античной культуры это Гомер, автор бессмертных «Одиссеи» и «Илиады»).

С развитием науки и искусства в древней Греции и Риме книга, записанная на пергаменте, и их авторы быстро завоевывают популярность в среде образованных людей. Хотя непонятно записывал ли сам Платон свои диалоги (говорят, что эту работу выполнили его ученики и слушатели), и он и Аристотель примеры мыслителей, философские и научные книги которых во многих экземплярах расходятся в полисах и государствах античности. Произведения Апулея, например, «Метаморфозы» и «Апология», - пример настоящих литературных произведений (предшественников романа и автобиографической повести).

другой глиняной книги «Невинный страдалец» жалобы героя:

«Толу, кто богу не совериал возлияний,

И за трапезой не взывал к богине,

Кто ниц не падал, не знал поклонов,

Чъих уст бежали мольбъ-молитвы,

Кто праздники не чтил, не блюл дни бога,

Бъл небрежен, презрел обряды,

Кто людей не учил поклонению и службе,

Не взывал к богу, съел (жертвенную) пищу,

Свою богиню бросил, не принес ей жертву,

Стал я подобен.

(А ведъ) сам я помнил о мольбе-молитве

Благоразумием (была мне) молитва, прави-

лом-жертва,

Денъ почитания бога (был) ублажением

Денъ процессий богини - прибълью

сердц̧а,

Молитва (за) цуаря - она же моя услада...

Хотел (бъ) я знать, что богу приятно;

Что хорочо человеку - преступленье пред богом,

Что для него отвратительно - хороио его

Кто волю богов в небесах узнает?» богу!

(там же, с. 120) 
Рукописная книга, но уже на бумаге практиковалась все средние века и частично в эпоху Возрождения. Она тоже была адресована аудитории грамотных людей «высокой культуры», состоявшей не только из философов и ученых, но и монахов, рыцарей, богатых горожан, образованной части двора королей, исполнителей их воли (первых чиновников). Здесь мы наблюдаем и первые попытки обслуживания книгой относительно больших аудиторий: известно, что в больших монастырях чтецы часто диктовали сразу для 30-40 переписчиков.

Изобретение печатного станка совпало, с одной стороны, с изменением аудитории (в XVI в. монастырская среда вытесняется университетской и городской), с другой - с появлением новых условий и требований, которые стали особенно настоятельными с формированием, начиная с XVII-XVIII вв., массового буржуазного общества, развития права, науки и искусства. Эти условия и потребности смогла удовлетворить новая книжная технология, ориентированная на массового читателя и большие аудитории, качество печати, экономию. Именно в этот период и сложилась столь привычная для нас бумажная печатная книга.

Конец XX и начало следующего века - бурное развитие вычислительной и цифровой техники, в результате которой появилась электронная книга. Родившее чудо оказалось весьма агрессивным по отношению к бумажной книге. Электронная книга и Интернет не только перехватывают читателей, но и влекут за собой исчезновение личных библиотек, сокращение тиражей бумажных книг, наконец, широко распространенный миф о том, что время традиционной книги окончательно ушло. Попробуем теперь взглянуть не на историю книги, a ее сущность. При этом нам придется представить книгу односторонне, как идеальный объект, поскольку рациональное научное объяснение предполагает обязательное абстрагирование. Но беря эти односторонние представления, будем рассматривать их в связи друг с другом, чтобы удержать целое.

Начнем с вопроса о происхождении книги. Понятно, что она не могла появиться без изобретения и развития пись- менности. Но это только одна из предпосылок, хотя и очень важная. Вторая предпосылка - формирование личности и общества, которое происходило на рубеже 6-4 столетия д.н.э. Кризис культуры древних царств (Шумеро-Вавилонской и древнеегипетской цивилизаций), состоявший, с точки зрения сознания индивида, в разочаровании относительно всесилия и поддержки богов, а также в переходе отдельных людей к самостоятельному поведению, повлек за собой становление нового антропологического типа - личности. Активные и инициативные индивиды сначала пишут письма своим личным богам

Богу, отцу моему, скажи! Так говорит Апиль-Адад, раб твой: Что же ты мною пренебрегаешь? Кто тебе даст (другого) такого, как я? Напиши богу Мардуку, любящему тебя: прегрешения мои пусть он отпустит. Да увижу я твой лик, стопы твои облобызаю. И на семъю мою, на больших и малых взгляни. Ради них пожалей меня. Помощь твоя пусть меня достигнет ${ }^{2}$.

Потом они пишут своим друзьям и правителям, как например, Платон или в эллинистический период Архимед. Параллельно они начинают записывать устные сказания и рассказы («авторы» мифа об Гильгамеше или Библии и Вед, Гомер и др.); в результате появляются первые книги. Спрашивается, зачем последнее, для чего записывать устные нарративы? Чтобы сохранить, конституировать складывающееся общество, задать ему направление развития. Дело в том, что именно общество решало вопросы жизни и смерти. Вот любимый мой кейс образование в XV веке империи ацтеков (общества, населявшие Мексиканскую долину, по уровню своего развития практически ничем не отличались от обществ интересующего нас периода).

В начале $X V$ века мехики жили в небольшом царстве. После избрания королем Итцкоатла, около 1424 года, мехики оказались перед трагическим выбором: или признать власть Максила, тира

${ }^{2}$ Там же. С. 46. 
на соседнего государства, или начать против него войну. Перед угрозой уничтожения король и мехиканские господа решили полностью подчиниться тирану, говоря, что лучше отдаться всем в руки Максила, чтобы он сделал с ними все, что пожелает, а быть может, Максил их простит и сохранит им жизнь. Именно тогда слово взял принц Тлакаэлель и сказал: "Что же это такое, мехиканцы? Что вы делаете? Вы потеряли рассудок! Неужели мы так трусливы, что должны отдаться жителям Ацкапутцалко? Король, обратитесь к народу, найдите способ для нашей защиты и чести, не отдадим себя так позорно нашим врагам». Воодушевив короля и народ, принц Тлакаэлель получил в свою власть управление армией, укрепил и организовал ее, повел на врага и разбил тирана. Затем он провел целый ряд реформ в области религии и государственного устройства ${ }^{3}$.

В данном случае король и мехиканские господа представляют собой общество: на собрании вопрос о судьбе страны они решали вне рамок государственных институтов, это было именно общественное собрание, где важно было убедить других (короля, жрецов, господ, народ - это все различные общественные образования, субъекты), склонить их к определенному решению и поступку. При этом в ситуации, угрожающей гибелью всех, каждый активный участник собрания становился как бы равным другому (например, принц королю). В ситуациях кризиса или заболевания социума люди переходят к общению, то есть собираются вместе вне рамок социальных институтов и главное пытаются повлиять на общественное сознание друг друга с целью его изменения. Результатом эффективного общения, как правило, является сдвиг, трансформация общественного сознания (новое видение и понимание, другое состояние духа - воодушевление, уверенность, уныние и т. п.), что в дальнейшем является необходимым условием перестройки социально значимого поведения. В этом смысле общество напряжено (структурировано) силовыми линиями поля социума, куда

3 Леон-Портилья М. Философия нагуа. М., 1961. C. 266-275. всегда возвращаются общающиеся (чтобы продолжать функционирование в соответствующих институтах). Но одновременно само общество есть своеобразное поле, силовые линии и напряженности которого задаются текущим взаимодействием (общением) всех участников, которые «здесь и сейчас» сошлись на общественном подиуме.

Каким образом, учитывая общество, нужно рассматривать человека? Он уже не субстрат культуры, а потенциальный носитель всей социальности, а также будущего социального устройства. Именно его активность, направленность и взаимодействие (общение) в рамках общества определяют возможную в перспективе структуру культуры, возможную в том смысле, что новая культура состоится (при этом возможность перейдет в действительность), если имеют место и другие необходимые для формирования культуры предпосылки (семиотические, ресурсные и прочее). Только становящаяся личность была способна на подобные поступки.

Как показывает Ханна Арендт личность, политика и свобода - три стороны одного целого. Например, личность в античности, по Арендт, это индивид, который, с одной стороны, избавлен от жизненной необходимости, поскольку он домохозяин и владеет рабами, с другой стороны, вне дома в публичном пространстве участвует как равный с равными в принятии социальных (политических) решений, затрагивающих судьбы полиса. Под политикой Арендт понимает совсем не то, что имеет в виду современный человек, слушающий по радио и телевидению выступление политических деятелей. Для Арендт политика предполагает личностное свободное поведение и действие (поступок), причем такие, которые, во-первых, ориентированы на социальные изменения, во-вторых, так сказать, интерсубъективны, т.е. могут достигнуть своей цели только при поддержке других личностей (общества) ${ }^{4}$.

\footnotetext{
${ }^{4}$ Характеристики свободного античного человека по Арендт совпадают с моей характеристикой «становящейся античной личности» (см. Розин В.М. Личность и ее изучение. М., 2004, 2012). «Греческое сло-

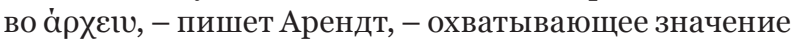
«начинать», «вести за собой», «править» (т.е. все, что отличает свободного человека), свидетельствует о
} 
Да, но каким образом личность может получить такую поддержку, если она действует самостоятельно и ее убеждения часто не совпадают с мнением других? Вот здесь и потребовались общие представления (ценности, картины реальности, история и прочее), консолидирующие разные личности, а также личность с обществом, конституирующие, так сказать, общее социальное пространство и направление движения - но, подчеркнем, принципиально при условии сохранения личности. Именно эту задачу наряду с другими средствами (философией, политикой, общими собраниями) и решала книга. С одной стороны, в ней собирались и воспроизводились нарративы, задающие указанные общие представления. С другой - она адресовалась отдельному человеку, грамотной, читающей личности. С третьей стороны, книга способствовала формированию и развитию общества.

Технически эти задачи решались за счет изобретения двух основных процессов: записи текста на определенном материальном носители (глине, папирусе, пергаменте, позднее бумаге) и локализации повествования (нарратива) в пространстве, удобном для чтения, хранения или передачи (ящик для глиняных книг, свитки, бумажная книга 5 ). Забегая вперед, стоит отметить, что хотя книга претерпела за века многочисленные трансформации, эти два процесса все равно сохраняются. Например, в настоящая

таком опыте, в котором состояние свободы и способность начинать нечто новое совпадали. Как мы сказали бы сегодня, свобода переживалась в опыте спонтанности. Это разностороннее значение сло-

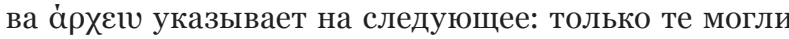
начать нечто новое, кто уже являлись правителями (а именно главами домохозяйств, правящими рабами и семьей) и тем самым освободились от оков жизненной необходимости, чтобы заняться свершениями в далеких землях или гражданскими делами в полисе; в обоих случаях они уже не правили, а были правителями среди правителей, вращались в кругу себе равных и, в качестве лидеров, заручались их помощью, чтобы начать нечто новое, новое предприятие. Ведь только с помощью других мог á $\rho \chi \varepsilon v$, правитель, начинатель и лидер, действовать

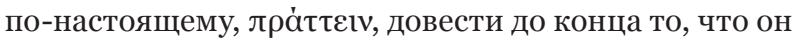
начал» (Арендт X. Что такое свобода // Между прошлым и будущим. М., 2014. С. 251).

${ }_{5}^{5}$ А в настоящее время это перфорационные, магнитные, оптические ленты и диски. время интересующая читателя книга может находиться на другом континенте как программа и информация в Облаке (идея облачных технологий следующая: можно не иметь никаких программ на своём компьютере, а иметь только выход в Интернет. Всё основное располагается в Интернете, сеть которого охватывает весь мир, и то, что тебе нужно, получишь где-то там.). Тем не менее, читатель всегда может вызвать и читать текст на своем экране, как будто открыл и листает бумажную книгу; другими словами, те же две операции.

Может показаться, что появление книги мало что изменило в восприятии и сознании индивида; даже Платон так думал, называя иронически своего гениального ученика (Аристотеля) книжником. Но это не так, книга кардинально изменила сознание читающего. Недаром М. Мамардашвили пишет, что в лоне книги рождается личность («роман, или текст, или произведение есть машина изменения самого себя» $)^{6}$, и он не преувеличивает. Что же меняется? Обратим внимание, что книга - это замкнутый мир событий, в другой книге - другой мир, кроме того, поскольку чтение книги линейно, в эти миры читатель входит постепенно, иначе говоря, он эти миры осваивает и проживает во времени. В результате под влиянием книг сознание человека начинает расчленяться на отдельные реальности (миры) и выявляется (конституируется) такое фундаментальное качество сознания как временность. Один из первых, кто это осознал, был св. Августин. В «Исповеди» он, по сути, говорит о том, что его жизнь не едина, а распадается на разные реальности и разворачивается во времени, причем в этих разных мирах существует именно он, его «Я», но как бы разное (в прошлом Августин не верил в Бога, в настоящем он пришел к вере, в будущем он укрепится в ней). Интересно, что подобное самосознание приходит к Августину не до «Исповеди», а в процессе ее написания; к читателю приходит в ходе ее прочтения. Можно указать и на другие трансформации сознания, обусловленные появлением книги. Формируется новая структура памяти (книга как программа запоминания). Складывает бо-

${ }^{6}$ Мамардашвили М. Лекции о Прусте. М. 1982. С. 354. 
лее сложное воображение: читая текст, приходится представлять события реальности, заданные в ней (конечно, слушая устную историю, это тоже нужно делать, но в книге возможности представить и запомнить разные события и перипетии на порядок выше). Но особенно большое воздействие книга оказала на мышление. Оформляя в книгах рассуждения и другие мыслительные построения, Платон (в лице его учеников) и Аристотель создали не только первые образцы философии и науки, но и показали, что научная книга выступает замечательным средством построения новой мысли.

Если же говорить о влиянии на общество, то придется указать не только на отдельные книги, но и на библиотеки. Этот институт помогал консолидировать общество и формировать новые социальные практики, например, научную. Известно, например, что в Александрийской библиотеке, насчитывающей по некоторым подсчетам историков до 700 ооо свитков, в эпоху эллинизма работали Евклид, Герон Александрийский, Архимед.

Только на первых этапах своего развития книга выполняла две своих основных функций (способствовала консолидации общества и направляла развитие личности), скоро обнаружилось (естественно в творчестве ее создателей и реакции читателей), что она позволяет путешествовать, развлекает, необходима для обучения, что в ней скрыты много других возможностей.

Однако пока мы говорили о рукописной книге. Почему она в конце концов была вытеснена печатной? Здесь главную роль, вероятно, сыграла демократизация общества и личности, начало которой относится к XV - XVI векам. До этого времени общество в Европе было сословным, грамотных людей было относительно немного (сравнительно с современностью), но главное, считалось, что грамота и чтение книг - привилегия высших сословий и богатых. Совершенно другую картину мы видим, начиная с указанного периода времени. Формируются либеральнодемократические институты, заявляются принципы равенства и свободы, отстаиваются права каждого человека как гражданина и члена общества. В том числе право личности на образование и участие в делах общества (парламент, выборы и пр.). Умение читать становится обязательным и поддерживается государством. Как следствие, аудитория читающих расширяется в геометрических пропорциях. В этих условиях рукописная книга (даже если она диктуется 30-40 переписчикам) совершенно не могла удовлетворить новые потребности.

Но было еще одно важное обстоятельство. Требование равных прав, новые институты образования и производства довольно быстро привели к формированию массовых популяций и аудиторий. В свою очередь удовлетворение их запросов вызвало к жизни технологизацию жизни, причем в разных областях (строительства, промышленности, образования, в том числе и производства книг). Для технологизации же, как показывает анализ, характерны установки на массовость, качество, стандарты, индустриальные способы изготовления. Изобретенный несколько раньше печатный станок полностью удовлетворял этим установкам: он позволяет индустриальными методами получить нужное качество, создать миллионные тиражи. В этом смысле печатная книга - плоть от плоти демократизации и технологизации жизни.

В настоящее время мы переживает еще одну революцию, пожалуй даже, более грандиозную. С точки зрения интересующей нас тематики, можно отметить три основных момента. Прежде всего под влиянием процессов глобализации, а также изобретения социальных технологий управления обществом (пиар, реклама, пропаганда, идеология, контролируемые выборы и судопроизводство, имитация демократических институтов) государство получило власть над обществом, а само общество погрузилось в кризис и стало умирать ${ }^{7}$ В связи с этим упало зна-

\footnotetext{
7 Известно, что российское общество расколото и подавлено властями, которые считают такое положение дел - необходимым условием управления нашим темным населением. Но оно не мертво, как недавно в «Эхо Москвы» утверждал Леонид Радзиховский. «В России, - говорил он, - некому и нечего демонстрировать. Общество наше абсолютно мертвое. Поэтому никакие НАТЫ его не разбудят. Это предполагает постепенное на разных уровнях в разных формах давление политическое, экономическое, информационное и так далее. По отношению к России. Я думаю, что нет такого какого-то четкого плана, вот шаг за шагом, вот это мы сделаем в таком году, это в таком. И в итоге мы режим обрушим. Такого плана я
} 
чение книги, одной из главных функций которой было консолидация общества.

Параллельно с опорой на новые вычислительные и информационные технологии (мобильная связь, Интернет, телевидение и др.) складываются новые сообщества (сетевые), и новые формы и способы консолидации людей в этих сообществах. Рассмотрим в связи с этим более подробно Интернет. Хотя первые интернетовские сети были закрытые (в военной области), очень быстро Интернет стал развиваться как открытая система, к которой имели доступ любые пользователи. Более того, они могли быть анонимными, выступая под собственными «никами» или «аватарами» ${ }^{8}$. В результате Интернет превращается в глобальную площадку, напоминающую греческую агору, на которую может выйти и общаться любой человек или группа, территориально находящиеся в любой точке земного шара. И в идеале высказываться они могут совершенно свободно, не боясь

думаю, у них конечно нет. Но общая установка на то, что нам с существующим в России режимом больше не по пути, эта установка я думаю, у них есть. А есть установка, она будет проявляться разными способами на разных местах» (http://echo.msk.ru/programs/ personalno/1380744-echo).

На мой взгляд, российское общество скорее больно, о чем свидетельствует поддержка населением нашей власти, нарушающей международные и собственные законы. Но сегодня общество болеет и спит, а завтра может пробудиться и начать исцеляться. Конечно только, если у людей сохраняются культурные и социальные связи и инстинкты жизни.

8 Впрочем, известно, что государства осуществляют контроль за пользователями Интернета. Один из примеров Китай, который «обладает одной из самых совершенных систем контроля интернета, которая включает как законодательную базу, так и систему фильтрования трафика. В этой стране гораздо жестче осуществляется политическая цензура, чем блокирование сайтов аморальной направленности. Порнография в Китае запрещена, но гораздо эффективнее блокируется доступ к информации о независимости Тибета и Тайваня, некоторые новостные службы («Би-би-си»), ресурсы о правах человека. Интересная особенность - Китай не афиширует политику ограничения контента. При попытке обращения к заблокированным ресурсам китайские пользователи получают сообщения об ошибке 404 или о других технических проблемах. При этом Китай активно развивает ресурсы на китайском языке» (Борис Лихтман, Андрей Сидельников Правительства берут интернет под контроль. http://www. infosecurity.ru/_gazeta/content/o91225/art2.shtml). быть подвергнуты остракизму или наказанию. Как уже отмечалось выше, в своих исследованиях Ханна Аренд показывает, что политическая жизнь зародились в Греции, где свободные от необходимости обеспечивать свою жизнь граждане (поскольку они были хозяевами и владели рабами) могли на агоре высказывать свои мнения, общаться, убеждая друг друга, участвовать в принятии решений, касающихся жизни полиса. В некотором смысле Интернет позволил возобновить политическую жизнь на разных территориальных уровнях (города, района, региона, страны) вплоть до планетарного. Пусть эта политическая жизнь пока ограниченная, но важно начало.

Открытый, свободный и отчасти анонимный характер доступа в Интернет обеспечил возможность использовать его совершенно разными субъектами и в разных целях: одни решали производственные или творческие задачи, другие общались, третьи воровали или разрушали, четвертые развлекались и играли, пятые призывали жить дружно, шестые, как исламские фундаменталисты, наоборот, требуют убивать неверных и американцев, седьмые, восьмые и т.д. Удовлетворить эти разнообразные и противоположные устремления и действия никакая искусственная техническая система не могла, смог живой организм, сложившийся на субстратной технической основе Интернета.

Можно указать еще один фактор, способствовавший становлению Интернета как глобального организма. Это кризис техногенной цивилизации, обусловивший переходной характер нашей цивилизации и времени. Дело в том, что мы живем в ситуации распада социальных структур при том, что новые, отвечающие современным вызовам, еще не сложились. Каким же образом тогда в ситуации перехода, пока неизвестно куда, сохраняются социальность и общности? С одной стороны, они тоже претерпевают напряжения и трансформации, но с другой - все же живут. Спрашивается за счет чего? Как всегда в этих случаях (ведь переходы от одной культуры и социальности к другим в истории уже были: от культуры древних царств - к античности, от античности - к средним векам, 
от средних веков - к новому времени) за счет общения и боръбы, а также обретения нового "социально-технического тела». Например, переход к культуре нового времени сопровождался, во-первых, сменой христианского мироощущения на рациональное (на первый план ставится не Бог, а выдвигаются реальности личности и природы), которое происходит в борьбе и социальной полемике (религиозные, идеологические и экономические войны). Во-вторых, развиваются естествознание, инженерия, индустриальное производство, рынок и целый ряд новых социальных институтов (буржуазных, либерально-демократических), поддерживавших экспансию человека в отношении природы и самого себя (Просвещение). Постепенно складывается техногенная цивилизация, социально-техническим телом которой выступают указанные практики и институты.

Не является ли Интернет подобным планетарным социально-техническим телом, позволяющим людям в ситуации современного кризиса и перехода сохранять и возобновлять социальную и политическую жизнь? Думаю, что да, ведь именно в Интернете мы можем продолжать действовать, общаться, бороться, предлагать решения, совершать поступки, несмотря на крах и паралич основных социальных норм и регулятивов (права, морали, нравственности, авторитета и прочее). Это тело достаточно парадоксальное: и сложная техническая система, и среда нашего обитания, и живой организм.

Если от планетарного масштаба вернуться к антропологическому, то можно отметить следующее: с одной стороны, Интернет и мобильная связь постепенно становятся еще одним социально-техническим телом человека (наряду с другими - электричеством, транспортом, жильем, одеждой и прочее) ${ }^{9}$, колоссально

\footnotetext{
9 Подобно тому как человек в городе передвигается со скоростью транспорта, «видит», например, вечером и ночью, пользуясь электрическим светом, в одежде или дома не боится холода или жары, подобно этому с помощью Интернета и мобильной связи он может разговаривать с человеком, находящимся на другом конце планеты, получать информацию прямо из Лондонской библиотеки, решать различные задачи, смотреть фильмы и многое-многое другое, невозможное вне этих средств.
}

расширяя его возможности, с другой стороны, существенно трансформируют его психику и отчасти телесность. Этот второй момент можно пояснить, анализируя сетевую природу обоих систем. Но сначала, что такое сеть?

Сеть, помимо субстратной технической основы (узлы, линии или каналы связи), представляет собой систему самостоятельных субъектов (индивидуальных или групповых) заинтересованных в связях друг с другом и осуществляющих трансакции, которые могут быть очень различными (предъявление информации, встречи и общения, создание друг для друга виртуальных или реальных ситуаций и прочее). Примерами могут выступать сайты в социальных сетях, где «друзья» обмениваются текстами, работают над укреплением и расширением содружества, реализуют себя в общении. Актуализируя себя в сети, индивид попадает в ситуацию (будем ее называть «индуцированной сетью»), в которой он вынужден вести себя в соответствии с требованиями сети и в этом смысле часто необычно. Состояния человека, индуцированные сетью, - это состояния, если пользоваться понятиями Л.С.Выготского, «опосредованные». Опосредованы они двояко: семиотически, т.е. текстами (последние могут быть и визуальными) и правилами (условностями) жизни в сети. Состояния, индуцированные сетью, трансформируют психику человека, погружая его в «сетевое бытие». Примером такого бытия является жизнь человека в Фейсбуке, имеющего 200-300 друзей и постоянно общающегося с ними. Другой пример, один из знакомых автора, который имеет три мобильника, практически отвечает на все звонки (или звонит сам) каждые пять-десять минут, не мыслит свою жизнь вне мобильной связи (даже ночью он всегда отвечает на звонки). Как правило, сетевое бытие требует быстрой реакции, не позволяет глубоко продумать вопрос, выливается в построение образа, которые ожидают другие участники трансакций (именно этот образ и посылается в сеть). В психологическом плане жизнь в сети обычно имеет два варианта развития. Первый, индивид расщепляется на два субъекта: обычного и, так сказать, сетевого (назовем последнего «сете- 
вым дублем»), и пытается как-то примирить их существование, что ему часто не удается. Второй вариант развития: индивид принимает сетевой бытие как основное, вживается в него, перестраивается, т.е. фактически он становится сетевым дублем. Заметим только, что данная картина - не эмпирическая, а идеально-типическая (по М.Веберу); реальный человек может в нее не укладываться. Так вот Интернет и мобильная связь порождают в массовом порядке как индивидов с диссоциированной (расщепленной) психикой, так и сетевых дублей.

Но вернемся к нашей теме. Понятно, что в современной ситуации, при тех тенденциях, которые мы рассмотрели, книга не может конкурировать с Интернетом, который берет на себя много ее функций; в том числе через Интернет мы получаем доступ к библиотекам и различным книгам.

Наконец, третий момент - уже обозначенный выше выход на сцену электронной книги. Она не только перехватывает функции бумажной книги, но и мимикрирует под нее. Хотите страницы - пожалуйста, и вот уже смена текста на экране сопровождается визуально пере- листыванием страниц. Хотите, чтобы как в книге текст не излучал - пожалуйста, в настоящее время разработаны электронные бумага и чернила, не травмирующие глаза ${ }^{10}$. Уверен, предел будет достигнут еще в нашем столетии. Появится электронная книга-планшет, которая внешне ничем не будет отличаться от бумажной книги. Те же самые на вид и ощупь бумажные страницы (листай сколько хочешь, на здоровье, можно воспроизвести даже запах типографской краски), но на самом деле - это книга-планшет, которую можно настроить на любую книгу, имеющуюся в Интернете. То есть электронная книга-планшет представляет собой все оцифрованные книги.

Означает ли это скорую смерть бумажной книги? Вовсе нет, хотя ей придется потесниться и искать новые ниши. Дело в том, что бумажная книга - это большая культура и традиция. А в современной культуре сохраняются и воспроизводятся все бывшие культурные традиции, начиная от архаической культуры. Если же говорить о книге вообще, то ей предстоит долгая жизнь, столь долгая, сколько будет существовать личность и общество.

\section{Библиография:}

1. Арендт Х. Что такое свобода // Между прошлым и будущим. М., 2014.

2. Борис Лихтман, Андрей Сидельников Правительства берут интернет под контроль. http://www. infosecurity.ru/ gazeta/content/091225/art2.shtml

3. Клочков И. Духовная культура Вавилонии: человек, судьба, время. М., 1983.

4. Леон-Портилья М. Философия нагуа. М., 1961.

5. Мамардашвили М. Лекции о Прусте. М. 1982.

6. Розин В.М. Личность и ее изучение. М., 2004, 2012

7. http://echo.msk.ru/programs/personalno/1380744-echo

8. https://ru.wikipedia.org/wiki/\%D0\%AD $\%$ D0\%BB $\%$ D0 $\%$ B5 $\%$ D0 $\%$ BA $\% D 1 \% 82 \% D 1 \% 80 \% D 0 \%$ BE $\%$ D0\%BD $\%$ D0\%BD\%D0\%B0\%D1\%8F_\%D0\%B1\%D1\%83\%D0\%BC\%D0\%B0\%D0\%B3\%D $0 \% \mathrm{~B} 0$

9. Розин В.М., Голубкова Л.Г. Дефицит как форма власти // Тренды и управление. - 2014. - 2. - C. 188 - 199. DOI: 10.7256/2307-9118.2014.2.11177.

\footnotetext{
10 Электронная бумага (англ. e-paper, electronic paper; также электронные чернила, англ. $e$-ink) технология отображения информации, разработанная для имитации обычной печати на бумаге и основанная на явлении электрофореза... электронная бумага формирует изображение в отражённом свете, как обычная бумага, и может хранить изображение
}

текста и графики в течение достаточно длительного времени, не потребляя при этом электрической энергии и затрачивая её только на изменение изображения. https://ru.wikipedia.org/wiki/\%Do\%AD\%D o\%BB\%Do\%B5\%Do\%BA\%D1\%82\%D1\%80\%Do\%BE\% Do\%BD\%Do\%BD\%Do\%Bo\%D1\%8F_\%Do\%B1\%D1\%8 3\%Do\%BC\%Do\%Bo\%Do\%B3\%Do\%Bo 


\section{References (transliterated):}

1. Arendt Kh. Chto takoe svoboda // Mezhdu proshlym i budushchim. M., 2014.

2. Boris Likhtman, Andrei Sidel'nikov Pravitel'stva berut internet pod kontrol'. http://www.infosecurity.ru/_ gazeta/content/091225/art2.shtml

3. Klochkov I. Dukhovnaya kul'tura Vavilonii: chelovek, sud'ba, vremya. M., 1983.

4. Leon-Portil’ya M. Filosofiya nagua. M., 1961.

5. Mamardashvili M. Lektsii o Pruste. M. 1982.

6. Rozin V.M. Lichnost' i ee izuchenie. M., 2004, 2012

7. http://echo.msk.ru/programs/personalno/1380744-echo

8. https://ru.wikipedia.org/wiki/\%D0\%AD $\% \mathrm{D} 0 \% \mathrm{BB} \% \mathrm{D} 0 \% \mathrm{~B} 5 \% \mathrm{D} 0 \% \mathrm{BA} \% \mathrm{D} 1 \% 82 \% \mathrm{D} 1 \% 80 \% \mathrm{D} 0 \% \mathrm{BE} \% \mathrm{D} 0$ $\% \mathrm{BD} \% \mathrm{D} 0 \% \mathrm{BD} \% \mathrm{D} 0 \% \mathrm{~B} 0 \% \mathrm{D} 1 \% 8 \mathrm{~F} \% \mathrm{D} 0 \% \mathrm{~B} 1 \% \mathrm{D} 1 \% 83 \% \mathrm{D} 0 \% \mathrm{BC} \% \mathrm{D} 0 \% \mathrm{~B} 0 \% \mathrm{D} 0 \% \mathrm{~B} 3 \% \mathrm{D} 0 \% \mathrm{~B} 0$

9. Rozin V.M., Golubkova L.G. Defitsit kak forma vlasti // Trendy i upravlenie. - 2014. - 2. - C. 188 - 199. DOI: 10.7256/2307-9118.2014.2.11177. 